Deutsch in Europa 
IDS $\mid \begin{aligned} & \text { LeIBNIZ-InSTITUT FÜR } \\ & \text { DEUTSCHE SPRACHE }\end{aligned}$

Jahrbuch 2020

Redaktion

Melanie Kraus 


\section{Deutsch in Europa}

Sprachpolitisch - grammatisch - methodisch

Herausgegeben von

Henning Lobin, Andreas Witt und Angelika Wöllstein

\section{DE GRUYTER}


ISBN 978-3-11-073519-2

e-ISBN (PDF) 978-3-11-073151-4

e-ISBN (EPUB) 978-3-11-073154-5

ISSN 0537-7900

Library of Congress Control Number: 2020952269

Bibliografische Information der Deutschen Nationalbibliothek

Die Deutsche Nationalbibliothek verzeichnet diese Publikation in der Deutschen

Nationalbibliografie; detaillierte bibliografische Daten sind im Internet über http://dnb.dnb.de abrufbar.

(C) 2021 Walter de Gruyter GmbH, Berlin/Boston

Satz: Joachim Hohwieler, Sandra V. Steinert-Ramirez

Druck und Bindung: $\mathrm{CPI}$ books $\mathrm{GmbH}$, Leck

www.degruyter.com 